\title{
Characterizing the Mechanical Properties of Cementitious Emulsion Grout for Semi-Flexible Mixture
}

\author{
Fatima A. Jawad ${ }^{1, a}$, Shakir F. Al-Busaltan ${ }^{1, b^{*}}$ and Mustafa A. Kadhim ${ }^{1, c}$ \\ ${ }^{1}$ Civil Engineering Department, University of Kerbala, Kerbala, Iraq.

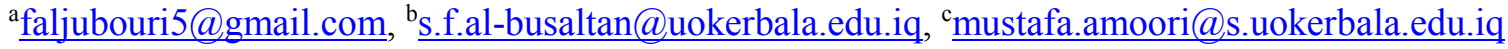

\begin{abstract}
Grout is a cement-based material with high strength and workability that allowing it to be injected into small cracks or leaky areas. It is usually used to patch concrete cracks or holes, but it may also be used to fill voids under metal bases or digging anchors. Furthermore, grout is used efficiently in the production process of semi-flexible pavement mixtures. The purpose of this study is to characterize the effect of grout ingredients on their mechanical properties. The grout ingredients were Ordinary Portland Cement (OPC), silica fume (SF), emulsion (Em), super-plasticizer (SP), and water. Different proportions of mentioned materials were used to characterizing the developed grout through flowability, compressive strength, and flexural strength tests. Results showed that the flow time decrease with an increase in the W/B. Also, the compression strength of the grouts comprised OPC+EM reveals an optimal dosage: i.e., 20\% EM. Moreover, SF generally leads to increase compressive and flexural strength. As the main conclusion, the mechanical properties of cementitious-emulsion grout are highly affected, but grout ingredient types, dosage, and properties.
\end{abstract}

Keywords: Bitumen emulsion; cementitious grout materials; compressive strength; flow ability; semi-flexible pavement; silica fume.

\section{Introduction}

Cement-based grouts are used widely in geotechnical applications [1]. Furthermore, cement grouts have been used in soil stabilization, precast construction, structural reconstruction, and other applications in civil engineering. Cement grout is widely used in different applications such as; jet grouting, soil grouting permeation grouting and rock grouting, coating prestressed cables in precast constructions, post-tensioned cable duct grouting, and ground stabilization close tunnels, are all applications for crack injection and filling holes in concrete structures [2-4]. The pumping of grouts when entering voids and cracks is directly related to their rheological properties. Estimating the penetrability of grout suspension is critical for the effective implementation of any grouting project.

It should be done before grouting because, for example, it decides the effectiveness of soil improvement and the overall cost of the project [5]. Cement pastes (also known as cement grouts) are fluid mixtures produce from cement, water, and possibly an admixture. Cement pastes have many applications, including filling, sealing, and consolidation, where their ingredient dosages influence their properties and application type. For example, the water/cement $(\mathrm{W} / \mathrm{C})$ ratio for prestressed cable coating ranges from 0.35 to 0.42 , while it for masonry repair and consolidation is in the range of 0.5 1 [1]. Cement grouts for soil or rock injection are highly fluid hydraulic binders with $\mathrm{W} / \mathrm{C}$ ratios varying from 1 to 2 . At the same time, $\mathrm{W} / \mathrm{C}$ ratios for sealing cement grouts are similar to those used for masonry repair, which varies between 0.5 and $1[6,7]$.

Fluidity, impermeability, strength, corrosion safety, sulfate resistance, and, in certain instances, frost toughness, are all performance requirements for a high-performance cementitious grout intended for structural repair. Reduced porosity, inhomogeneity, and microcracks in the cement grout and transition zone allow high efficiency [8,9]. Cement grouts are made up of cement and water, with or without sand and other additives. Admixtures are used to boost the flowability, permeability, and strength of grout. The most popular admixture in grout mixes is super-plasticizers (SP). More water and super-plasticizer will be needed to achieve the desired workability [10]. Due to its excellent capacities to increase the strength of grout, mortar, or concrete, silica fume is one of the most effective mineral admixtures [11-14]. On the other hand, Semi-flexible pavement (SFP) is a pavement type that is built in two phases. In the first, an asphalt mixture of $20-35$ percent air void is laying, then 
grouts (cement mortar or cement paste) are poured within the asphalt mixtures in the second step. The mixture is cured for a period of time that varies depending on the grout compounds and the thickness of the asphalt mixture[15,16]. The problem could be solved by using a more suitable grouting material with strong flexibility and interface bonding properties with the asphalt mixture.

The cement asphalt emulsion paste (CAEP) gathers between cement mechanical properties and the asphalt durability properties and is used as grouting material for SFP. It is composed of several components: cement, fine sand, and asphalt emulsion with several chemical admixtures [17]. In fact, cement-asphalt emulsion composites have a variety of industrial applications. The road industries prefer utilizing cold recycled asphalt mixtures and cold mix asphalt pavement for maintenance rather than hot asphaltic mixtures because they contribute to lower emission of $\mathrm{CO}_{2}$ to the air relatively and require less energy to produce [17-21]. Further, CAEP (which relatively lower cost production than polymer cement composite) can be used as a strong waterproofing and repair medium in the construction industry [22-24]. Therefore, this study aims to find the effect of the use of silica fume, emulsion, and super-plasticizer on the mechanical properties of the grouts used in the semi-flexible mixture.

\section{Experimental work}

Materials. Ordinary Portland cement (CEM I 42.5R) was used in this study, which is with the limits of the Iraqi requirements according to specification No: 5/1984 type I. the physical and chemical properties of such type of cement are listed in Table 1.

Table 1. Physical and chemical properties of OPC.

\begin{tabular}{cc}
\hline \multicolumn{2}{c}{ Physical properties } \\
\hline $\begin{array}{c}\text { Specific Surface Area }\left(\mathrm{m}^{2} \backslash \mathrm{kg}\right) \\
\text { Density }\left(\mathrm{gm} . \mathrm{cm}^{2}\right)\end{array}$ & 410 \\
\hline Chemical properties (\%) & 2.987 \\
\hline $\mathrm{SiO}_{2}$ & 18.1 \\
$\mathrm{Al}_{2} \mathrm{O}_{3}$ & 3.05 \\
$\mathrm{Fe}_{2} \mathrm{O}_{3}$ & 5.45 \\
$\mathrm{CaO}$ & 62 \\
$\mathrm{MgO}$ & 1.38 \\
$\mathrm{~K}_{2} \mathrm{O}$ & 0.760 \\
$\mathrm{Na}_{2} \mathrm{O}$ & 1.714 \\
\hline
\end{tabular}

Asphalt emulsion was supplied from Fosroc Company (under the commercial name of Nitoproof 10). Table 2 summarizes the Nitoproof 10 properties given by the manufacture [25].

Table 2. Properties of asphalt emulsion.

\begin{tabular}{|c|c|c|c|}
\hline Property & Standard ASTM & Limits & Results \\
\hline Emulsion type & D2397 [26] & $\begin{array}{l}\text { Rapid, medium and slow- } \\
\text { setting }\end{array}$ & $\begin{array}{l}\text { Medium-setting } \\
\text { (CMS) }\end{array}$ \\
\hline Color appearance & & & Dark brown liquid \\
\hline Residue by evaporation, $\%$ & D6934 [27] & Min. 57 & 60 \\
\hline Specific gravity, $\mathrm{gm} / \mathrm{cm}^{3}$ & $\mathrm{D} 70[28]$ & ------- & 1.03 \\
\hline Penetration, $\mathrm{mm}$ & D5 [29] & $100-250$ & 235 \\
\hline Ductility, $\mathrm{cm}$ & D113 [30] & Min. 40 & 44 \\
\hline $\begin{array}{l}\text { Viscosity, rotational paddle } \\
\text { viscometer } 50^{\circ} \mathrm{C} \text {, mPa.s }\end{array}$ & D7226 [31] & $110-990$ & 225 \\
\hline Freezing & D6929 [32] & Homogenous, broken & Homogenous \\
\hline Solubility in trichloroethylene, $\%$ & D2042 [33] & Min. 97.5 & 97.8 \\
\hline $\begin{array}{l}\text { Emulsified asphalt/job aggregate } \\
\text { coating practice }\end{array}$ & D244 [34] & Good, fair, poor & Good \\
\hline Miscibility & D6999 [35] & ------- & Immiscible \\
\hline Aggregate coating & D6998 [36] & ------- & $\begin{array}{l}\text { Uniformly- } \\
\text { thoroughly coated }\end{array}$ \\
\hline
\end{tabular}


CONMIX provided silica fume (SF). SF, also known as condensed silica fume or micro silica, is a fine powder with a high concentration of amorphous silicon dioxide [16]. This substance is a byproduct of the smelting of silicon and ferrosilicon [37]. The used SF's physical and chemical properties can be shown in Table 3.

Table 3. Physical and chemical of SF.

\begin{tabular}{|c|c|c|}
\hline \multicolumn{2}{|c|}{ Physical properties } & \multirow{2}{*}{$\frac{\text { Specification, ASTM C1240 }}{15000}$} \\
\hline Surface area $\left(\mathrm{m}^{2} / \mathrm{kg}\right)$ & 18100 & \\
\hline Density & $700\left(\mathrm{~kg} / \mathrm{m}^{3}\right)$ & - \\
\hline \multicolumn{2}{|c|}{ Chemical properties $(\%)$} & Specification, ASTM C1240 \\
\hline $\mathrm{NaO}$ & 1.534 & - \\
\hline $\mathrm{MgO}$ & 0.432 & - \\
\hline $\mathrm{Al}_{2} \mathrm{O}_{3}$ & 0.091 & - \\
\hline $\mathrm{SiO}_{2}$ & 92.05 & $>85 \%$ \\
\hline $\mathrm{Cl}_{2} \mathrm{O}$ & 0.001 & - \\
\hline $\mathrm{K}_{2} \mathrm{O}$ & 1.886 & - \\
\hline $\mathrm{CaO}$ & 3.035 & - \\
\hline $\mathrm{TiO}_{2}$ & 0.002 & - \\
\hline $\mathrm{MnO}$ & 0.149 & - \\
\hline $\mathrm{Fe}_{2} \mathrm{O}_{3}$ & 0.448 & - \\
\hline $\mathrm{CO}_{2}$ & 0.006 & - \\
\hline $\mathrm{CuO}$ & 0.017 & - \\
\hline $\mathrm{ZnO}$ & 0.179 & - \\
\hline $\mathrm{SrO}$ & 0.016 & - \\
\hline $\mathrm{Y}_{2} \mathrm{O}_{3}$ & 0.005 & - \\
\hline $\mathrm{BaO}$ & 0.057 & - \\
\hline LOI & 0.01 & $<6 \%$ \\
\hline Moisture & 0.05 & $<3 \%$ \\
\hline
\end{tabular}

Super-plasticizer (SP) was supplied by LYKSOR Company (under the trade name Nano-Flow 5500). Nano-Flow 5500 is a polycarboxylate-based, high-range water reducer/super-plasticizer type of chemical admixture designed for the production of very flowable concretes or self-compacting concrete; Nano-Flow 5500 provides very high flow-ability and slump retention performance. Table 4 shows the properties of the used super-plasticizer, Type G-water-reducing, high range, and retarding admixtures, according to ASTM C494.

Table 4. Properties of super-plasticizer.

\begin{tabular}{ccc}
\hline Property & Value & Specification \\
\hline Color and form & Yellowish-liquid & - \\
Chemical base & Polycarboxylate & - \\
Density $(\mathrm{kg} / \mathrm{lt})$ & 1.06 & $1.05-1.09\left(\mathrm{at}+20^{\circ} \mathrm{C}\right)$ \\
Chloride ion content & 0.05 & Max $0.1 \%-$ Chloride free acc.to EN 934-2) \\
Alkali content & $3 \%$ & Max. 5\% \\
$\mathrm{pH}$ & 4 & $3-7$ \\
Conformity & - & ASTMC494 Table 1 \\
\hline
\end{tabular}

Methods. The investigation program included two stages, the first aimed to specify the optimum W/B ratio (Water/ Binder, the binder is $\mathrm{OPC}+\mathrm{SF}$ ), while the second is for optimizing the emulsion content. The developed grouts were designed to replace OPC with other materials and different proportions of water in the first stage, different percentages of water were used, ranging from $(0.3$ to 0.45$) \%$ of binder weight. The proportion of a super-plasticizer dosage is constant as $2 \%$ of the weight of the binder. The SF replacement proportions were decided as recommended by previous research work [38] to confirm reliability. In the second stage, OPC was replaced with 20,40 , and $60 \%$ of OPC emulsion ratios. Also, as recommended by previous studies [39], the W/B ratio was constant as $40 \%$ for all stage two investigations. Table 5 shows the matrix of cementitious grout. 
Table 5. Matrix of cementitious grout.

\begin{tabular}{ccccccc}
\hline Mix & Stage & OPC, $\%$ & S.F\% & EM, $\%$ & W\B & S.P, $\%$ \\
\hline M0 & & 95 & 5 & 0 & 0.3 & 2 \\
M1 & \multirow{2}{*}{ one } & 95 & 5 & 0 & 0.35 & 2 \\
M2 & & 95 & 5 & 0 & 0.4 & 2 \\
M3 & & 95 & 5 & 0 & 0.45 & 2 \\
\hline M4 & \multirow{2}{*}{ two } & 75 & 5 & 20 & 0.4 & 2 \\
M5 & 55 & 5 & 40 & 0.4 & 2 \\
M6 & & 35 & 5 & 60 & 0.4 & 2 \\
\hline
\end{tabular}

Preparation of grouts. The grout samples were prepared in the laboratory under appropriate conditions and at the laboratory temperature. Firstly, the water was mixed with the super-plasticizer for a minute or more to obtain a homogeneous liquid. Secondly, Silica fume is added to this mixture, then OPC is added at a regular mixing speed. The produced grout is directly applied for either fluidity test or cast the required cubes or prisms. After the casting process, the samples were left in the molds to dry for one day or more, and they are demolded and placed in water until the day of the testing. Figure 1 shows the preparation of grout.

\section{Grouting materials tests}

The testing methods included

1) Fresh grout test (Fluidity test): The flow time is used to determine the fluidity of grouting materials conform to the ASTM C 939-10 [40]. The flow cone was filled with $1750 \mathrm{~mL}$ of grouting materials while the outlet was closed, and the efflux time was registered when the grouting material was fully discharged from the flow cone.

2) Hard-paste test (Compressive and flexural strength tests): The compressive strength test for the grout cubes was performed according to ASTM C 942-10 [41-43] for ages of 3, 7, 14, 28, 56, and 96 days. In addition, standard-dimensional molds that adhere to ASTM C 348-14 [44] were used to measure the grout's flexural strength at 3, 7, and 28 days. This test is conducted on hardened grout. Figure 2 shows the devices used to test the grout.
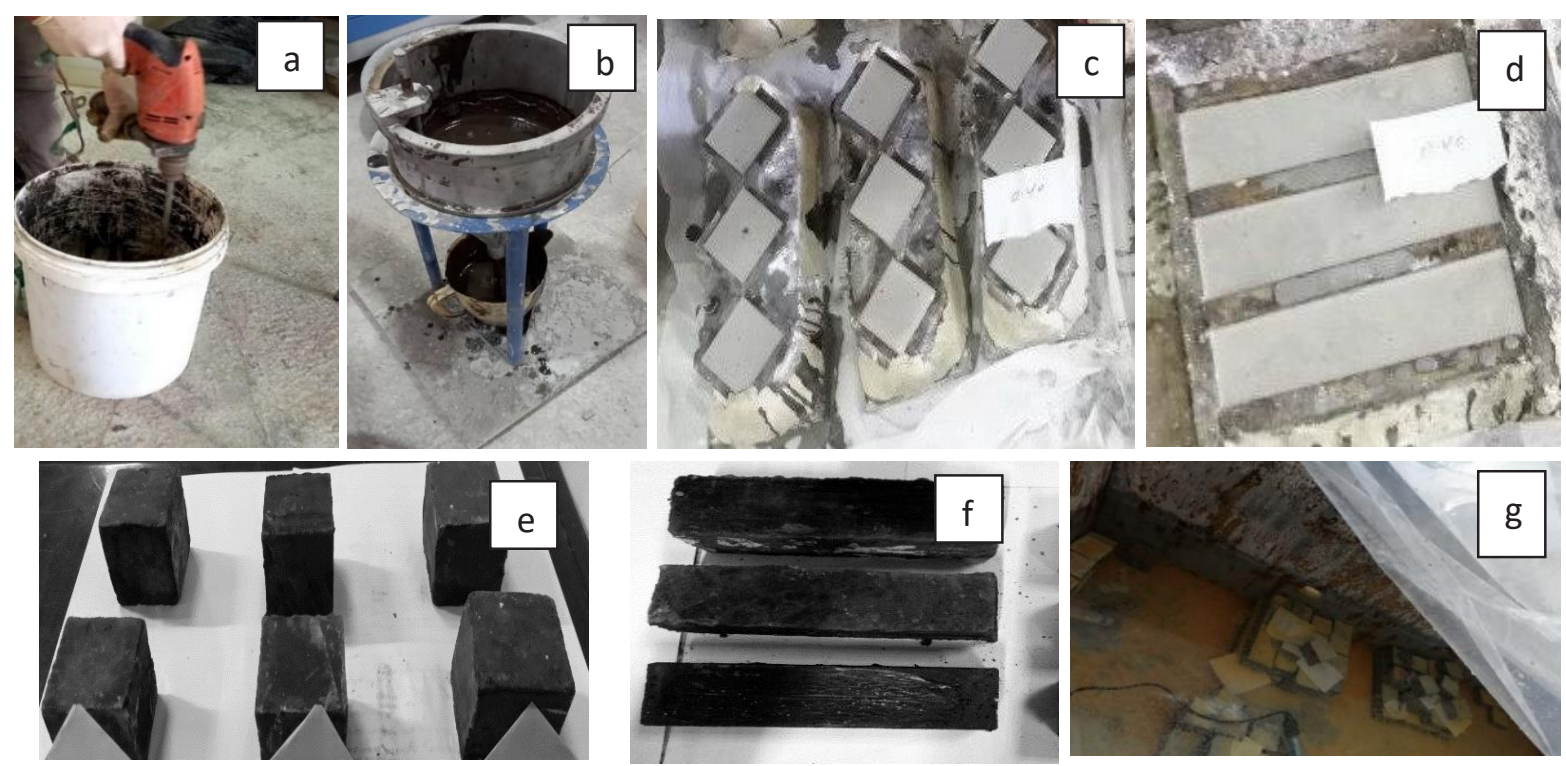

Figure 1. Grouts and samples preparation: a) mixing, b) fluidity test, c) cubs casting, d) prisms casting, e) cubes demolded, f) prism demolded, and g) curing. 


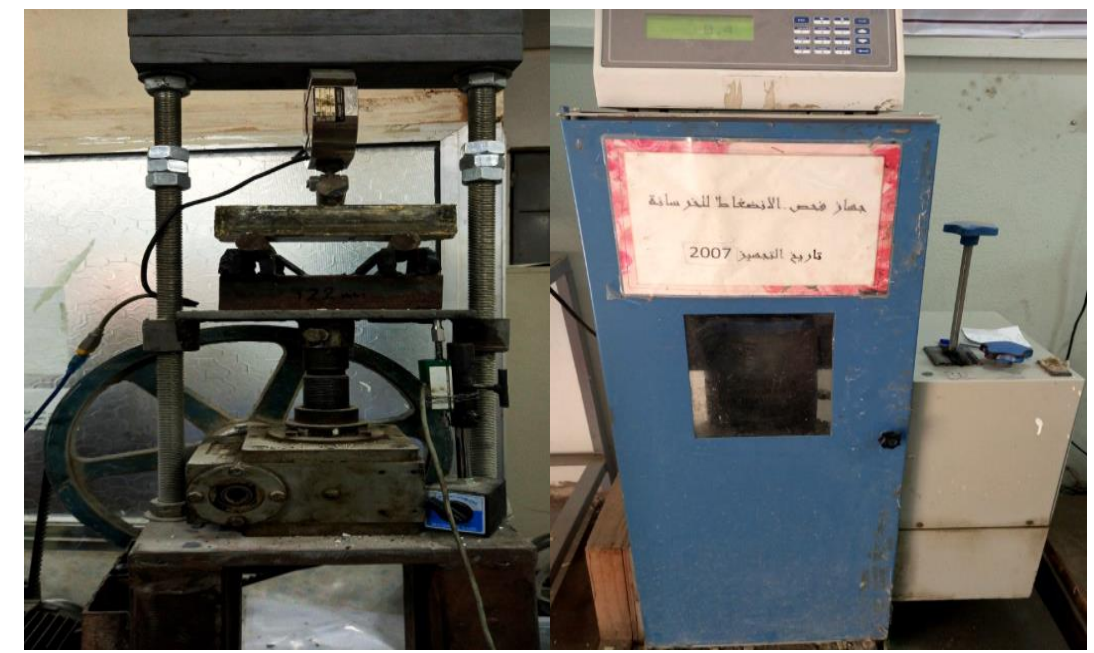

a) Compressive strength device

b) Flexural strength device

Figure 2. Mechanical test machines.

\section{Results and Discussion}

The following subsections discuss the results of the flow test, compression, and flexure strength of all mixtures at various ages:

Fluidity of cementitious grout. The results of the fluidity are shown in Figure 3. The results demonstrate that mixtures M0 to M3, which contains variable percentages W/B showed that the fluidity decreases with increasing the percentage of $\mathrm{W} / \mathrm{B}$, the highest flow value is $19 \mathrm{~s}$ which was produced by $30 \%$ of $\mathrm{W} / \mathrm{B}$ and lower flow value is $9 \mathrm{~s}$ which was produced by $45 \%$ of W/B. Based on the previous works, the range of flow time from $11 \mathrm{~s}$ to $16 \mathrm{~s}$ and that the mixture M1, M2 is within the range, while the mixture M0, M3 is not within the range $[38,45]$. The mixture M0 is the control, and the flow time is 19 seconds, and the time for it is considered $100 \%$, so the mixtures are M1, M2, $\mathrm{M} 3$, their ratio for the control mixture is 21,42 , and 53, respectively, and this shows that with the increase in water the percentage of change of these mixtures decreases with respect to the control mixture. The test results reveal that grout liquidity and flowability can be enhanced with a higher W/B ratio. Such modification permits the grout to flow faster from the discharge tube, confirming the reference results [38]. To ensure the higher workability of the grout, SP was added to the mixture. Grout slurries with a W/B ratio of 0.40 to 0.45 reflected higher workability, which interns confirmed in reference findings [46]. Addition of SP grants better cement particles, which reflected higher paste fluidity. It was determined from a study that a factor affecting workability was the water content of the mix since by simply adding water, the interparticle lubricant is increased. The higher the water/binder ratio, the lower the viscosity because the flow time is inversely proportional to the water content.

The mixtures from M4to M6, showed that with increasing the level of emulsion, fluidity is decreased. This result is agreed by previous research [39]. This result resulted in lower emulsion ratios to obtain high fluidity and suggested using lower emulsion ratios to increase the fluidity or decrease the flow time. Flow time increases by increasing the proportion of emulsification because emulsion occurs in the coalescence process, which reduces workability. Based on the previous works, the range of flow time from $11 \mathrm{~s}$ to $16 \mathrm{~s}$ and that the mixture M4, M5and M6 is within the range $[38,45]$. They used it when adding the emulsion, the percentage of $\mathrm{W} / \mathrm{B}$ is $40 \%$, which is the M2 mixture because it took less time and within the suggested range, and we do not use less than 11 seconds because the material becomes with a high amount of water and air and thus cement does not penetrate through the mixture. We have added emulsion to the mixture to obtain ductile cards and that the concrete is brittle and breaks easily. As for the asphalt, its durability is high. The mixture M2 is the control mixture, and that the percentage change for mixtures M4, M5, and M6 is 0, 9, and 18, 
which indicates that mixtures containing emulsion increase with the increase in the proportion emulsion.

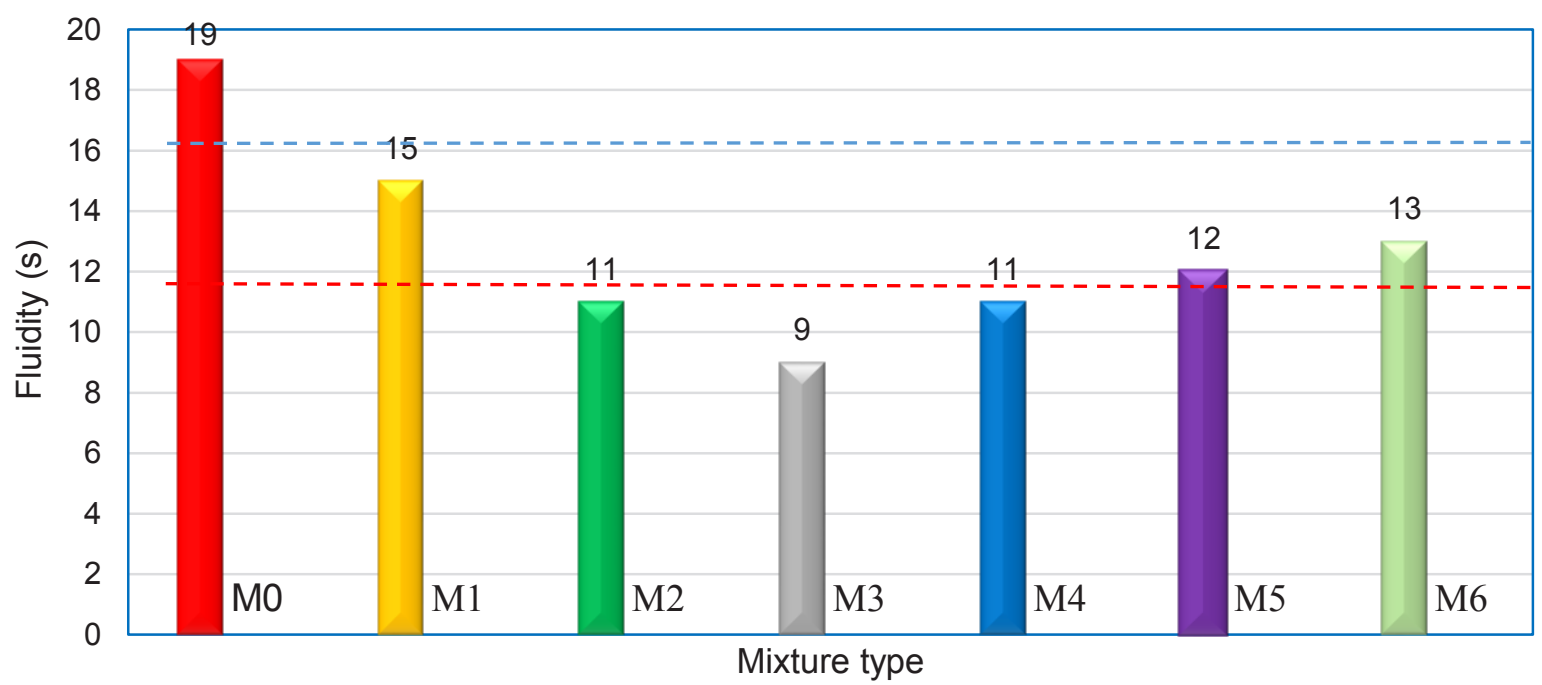

Figure 3. The fluidity of cementitious grouts.

Compressive strength of cementitious grout. The compressive strength of cementitious grout cubes $50 \times 50 \times 50 \mathrm{~mm}$ was studied with three cubes for each age at $3,7,14,28,56$, and 96 days. Figure 4 shows the compressive strength for pastes at different W/B ratios. The mixtures from M0 to M3 showed that the compressive strength increases for all mixtures with increasing age because cement needs time to complete its hydration process and reach relatively mature strength [16]. This is interesting as SF normally increases the compressive strength of the concrete mix. The majority of compressive strength of all mixtures was gained at an early age (i.e., 14 days). After 28 days, the gain in strength is less noticeable. The mixture M0 containing 30\% W/B the control and the percentage change in compressive strength for mixtures M1, M2, M3 regarding the control mixture, $(22,40$, and 19) MPa respectively appeared. And it seemed that I have the highest compressive strength using $40 \%$ water, which is considered the best. After that, the compressive strength decreases because of the silica fume and the cement added needs enough water to complete the hydration process and that for a certain extent, the water increase causes a decrease in the compressive strength because the water will occupy space after it does not dry out, and these voids will be weak places. It caused a decrease in compressive strength. The increase in the water content resulted in an increase in the compressive strength of the M0, M1, and M2 mixture, but at the same time, the flow time decrease. On the contrary, the M3 mix decreases the compressive strength with the increase W/B and the flow time decrease. For this reason, we must balance the ratio of added water and resistance.

The compressive strength of the pastes (M4, M5, and M6) decreases with the increased emulsion. Asphalt is much softer than cement hydrates. Therefore, the compressive strength of grouting pastes progressively decreases with rising asphalt emulsion content, as confirmed by a previous study [24]. Meanwhile, Figures 5 and 6 displays that the compressive strength growth rate is significant higher for all pastes when compare with control paste. This is because the emulsifier in asphalt emulsion significantly impacts cement hydration at an early age. Furthermore, the compressive strength of mixtures is connected to the creation of an asphalt emulsion film, which is also influenced by curing time. As a result, adding asphalt emulsion to a regular mixture not only decreases its compressive strength but, also slows down its hardening rate. The addition of water from the emulsion affects the resistance to compression, as the coalescence process occurs, which is emulsions droplets are naturally unstable and insoluble in water; with time (it could be hours or years). The bitumen phase will ultimately disconnect from the water and break down, and the droplets will combine small charges instigate the creation of the bitumen emulsion droplets; these charges come from two sources, the emulsifier and the ionic components in the bitumen itself. 


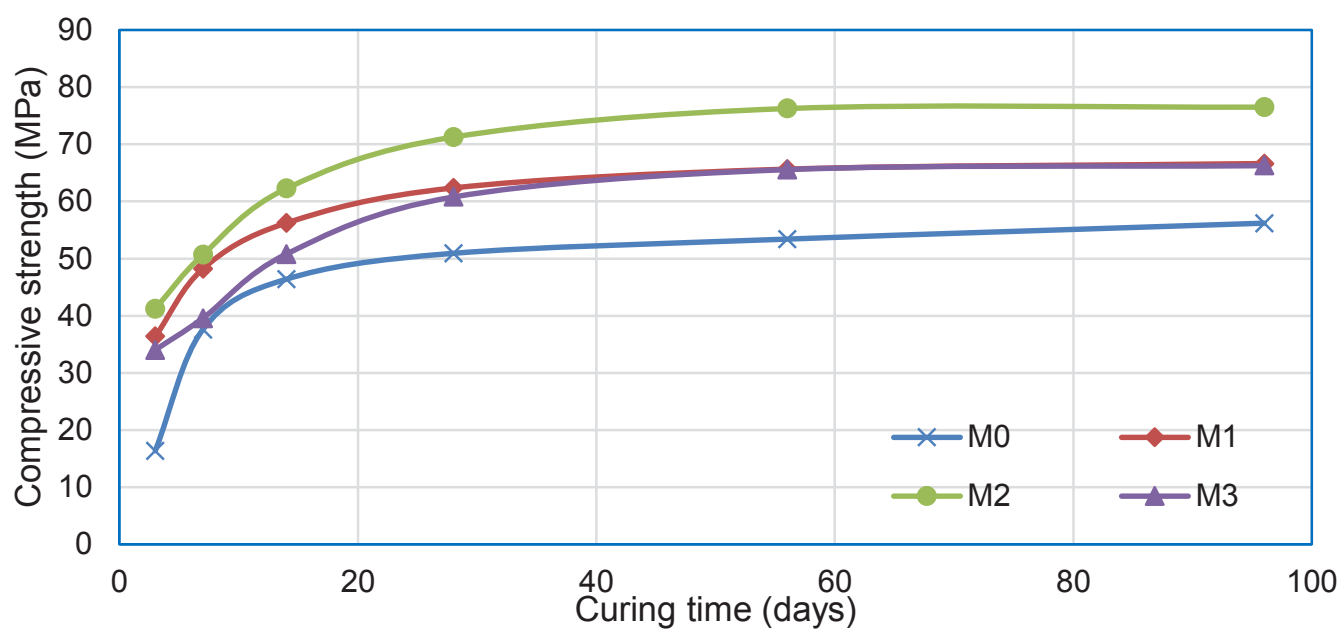

Figure 4. Compressive strength of pastes comprising different W/B ratios.

Consequently, an electrostatic barrier is initiated on the droplets' surface due to these small charges; this barrier prevents bitumen droplets from approaching each other. Thus, flocculation results when bitumen droplets have enough energy to overpower the electrostatic barrier, where droplets start to approach and adhere. This flocculation can be averted in different ways, such as adding more emulsifiers, agitation, and dilution. The mixture M2 is the control mixture, so that the rate of change for M4, M5, and M6 is 58, 70, and 74, respectively. This illustrates that in the mixtures containing emulsion, the compressive strength is reduced by increasing the proportion of emulsion and flow time.

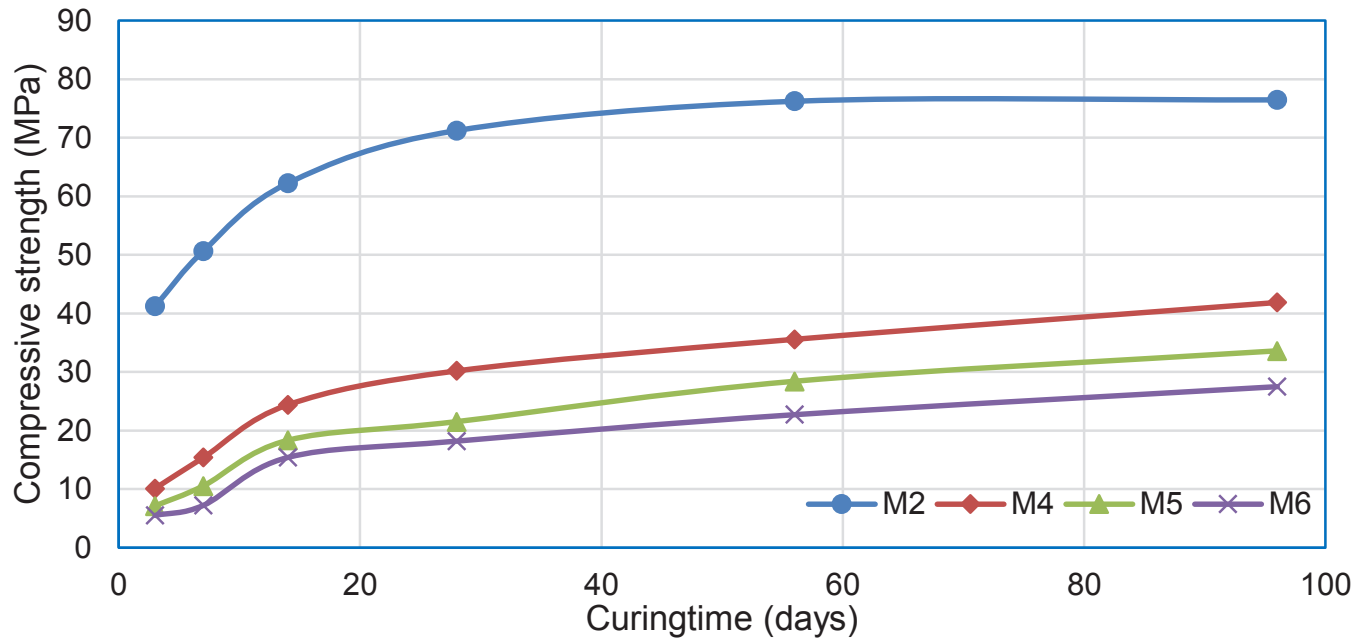

Figure 5. Compressive strength of paste comprising emulsion.

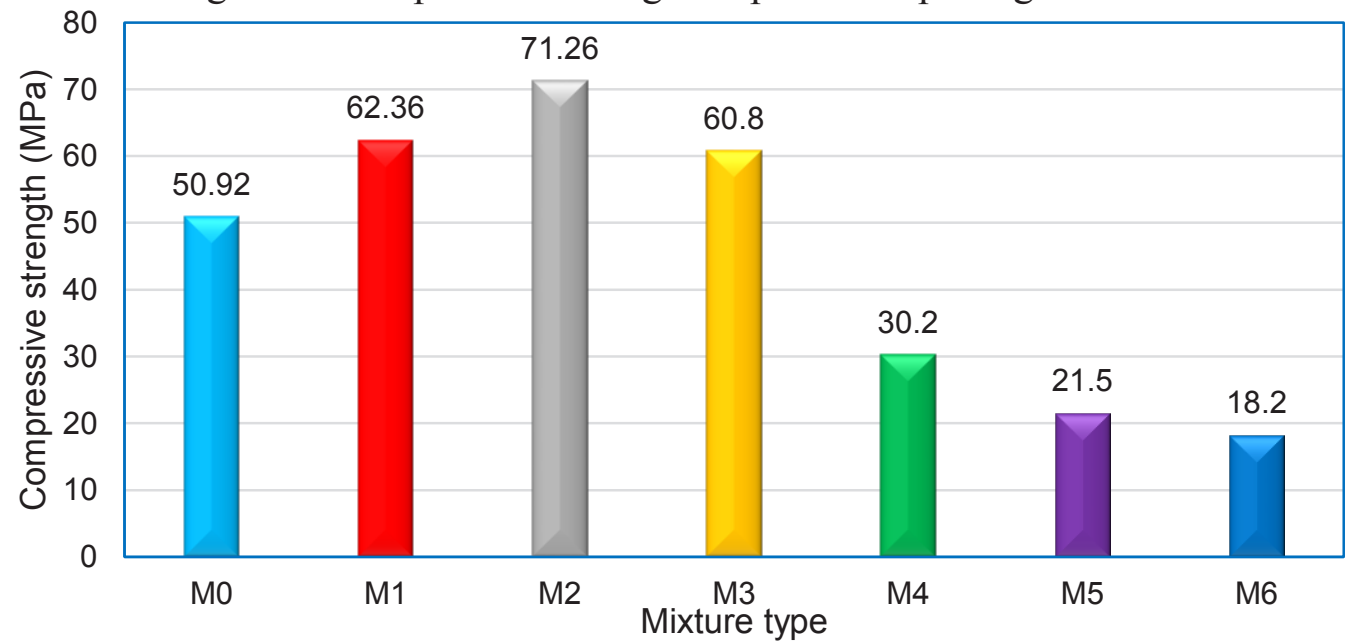

Figure 6. Compressive strength of Pastes at the age of 28 days. 
Flexure strength of cementitious grout. Figure 7 shows the flexural strength of the mentioned pastes at ages of 3, 7, and 28 days. The flexural strength was examined after 3,7 , and 28 days. The flexural strength of mixtures notation from (M0-M3) shows that it increases with the increase in life and that $40 \% \mathrm{~W} / \mathrm{B}$ has the highest flexural strength. Koting et al. [47] showed that using $30 \%$ water provides the highest flexural strength. Incorporating an adequate amount of SP resulted in a sufficient fluidity improvement of the grout mixture, which leads to infiltrating the composition through the compacted aggregates skeleton with the help of gravity action. Moreover, such an addition resulted in a batter dispersion of cement particles to reflect higher grout fluidity. The mixture M0 containing 30\% W/B the control and the percentage change in flexural strength for mixtures M1, M2, M3 regarding the control mixture, $(9,42$, and 22) MPa respectively appeared. And it appeared that I have the highest flexural strength using $40 \%$ water.

The mixtures from (M4-M6) indicate that the flexural strength decreases with the increase in the emulsion percentage and that the emulsion percentage of $20 \%$ has the highest flexural strength. On the contrary, Zarei et al. [39] showed that using 60\% emulsion ratio has the highest flexural. Also, they stated that the dosing of asphalt emulsion within the mix has an insignificant effect on the overall paste flexural strength. In this study, the noticeable emulsion harms the flexural strength; it is reduced up to $62 \%$ in comparison between M2 and M6 because of the ability of asphalt to adhere with aggregates which reflected better strength. In general, the ratio of flexural to the compressive strength of the grout was decreasing significantly with the higher addition of asphalt emulsion. The previous refers that the grout's toughness property increased with a higher amount of asphalt emulsion. On other side, reduction of toughness value could be a feature for the durability and flexibility of SEP. The mixture M2 containing 40\% W/B the control and the percentage change in flexural strength for mixtures M4, M5, M6 regarding the control mixture, (30, 58, and 62) MPa respectively appeared, as can be seen in Figure 8. It seems that the flexural strength rate increases with the increase of emulsion depending on the mixture control.

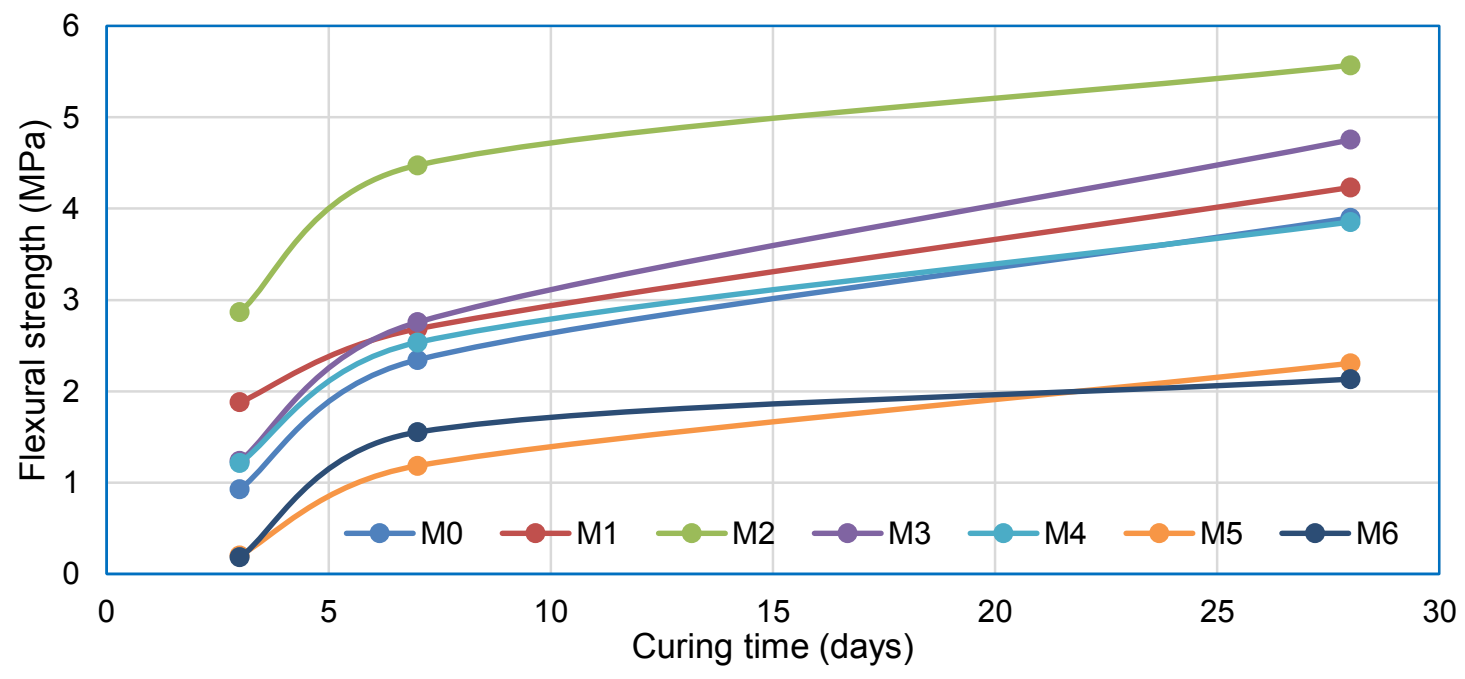

Figure 7. Flexural strength of cementitious grout pastes. 


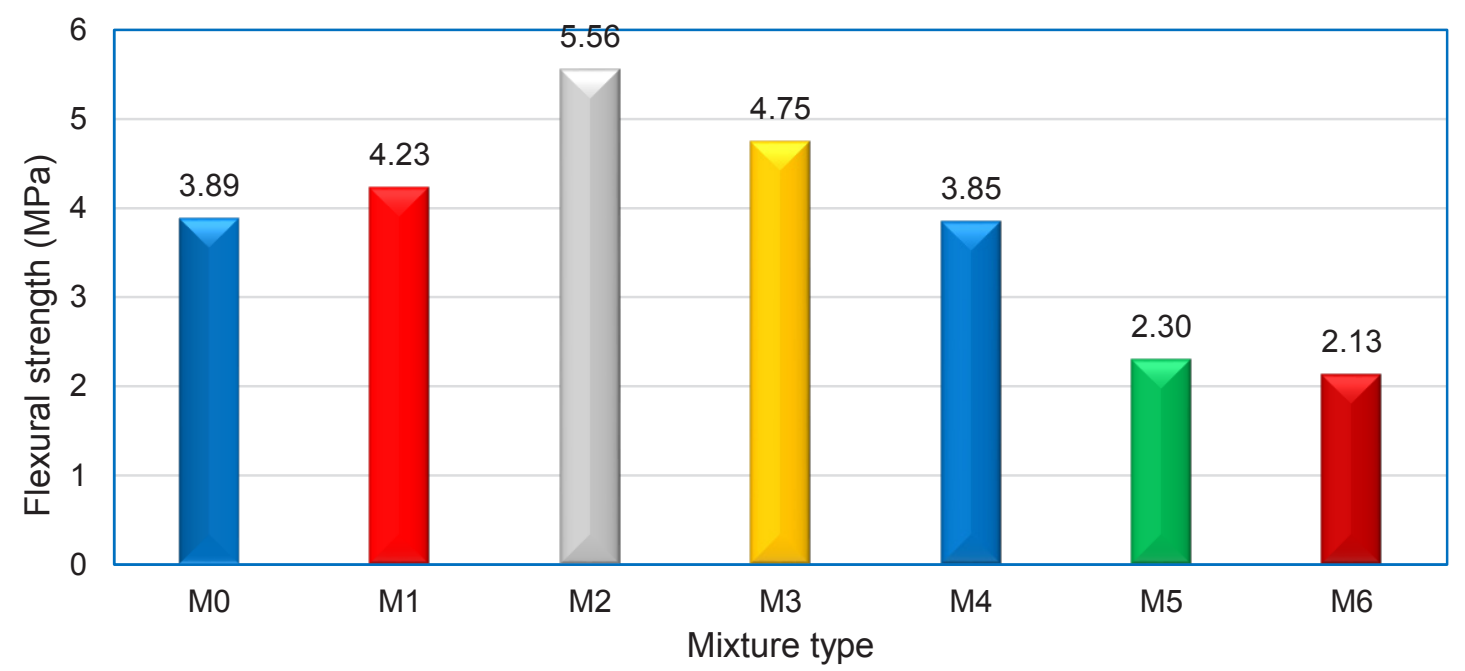

Figure 8. Flexural strength of cementitious grout pastes at 28 days.

\section{Conclusions}

The grout of SFP is an essential part that determines the properties of such mixture; therefore, the characterizing of grout concerning its contents is necessary. The following conclusion draws from the experimental results of grouts comprising various contents:

- Flow time decreases with increasing water percentage, while it is increased with increase emulsion percentage.

- The use of $40 \% \mathrm{~W} / \mathrm{B}$ has the highest compressive strength, and with increasing age, the compressive strength increases.

- $20 \%$ EM replacement of OPC in grout production is the optimum value when the required properties govern mechanical properties.

- The increase in W/B increases the compressive strength of the mixtures (M0, M1, and M2) and the flow time increase. As for the mixture M3 with the rise in water percentage, its compressive strength decreases, and the flow time decreases.

- With an increase in the emulsification percentage, the compressive strength decreases and the flow time increases.

\section{Acknowledgment}

The authors appreciate the assistance in obtaining materials from the Karbala city directorate of project implementation. The highway laboratory staff at the University of Kerbala must also be thanked for their help.

\section{References}

[1] Celik, F. and Canakci, H., 2015. An investigation of rheological properties of cement-based grout mixed with rice husk ash (RHA). Construction and Building Materials, 91, pp.187-194.

[2] Müller, U., Miccoli, L. and Fontana, P., 2016. Development of a lime based grout for cracks repair in earthen constructions. Construction and Building Materials, 110, pp.323-332.

[3] Lacerda, M.M.S., da Silva, T.J., Alva, G.M.S. and de Lima, M.C.V., 2018. Influence of the vertical grouting in the interface between corbel and beam in beam-to-column connections of precast concrete structures-An experimental analysis. Engineering structures, 172, pp.201-213.

[4] Tullini, N. and Minghini, F., 2016. Grouted sleeve connections used in precast reinforced concrete construction-Experimental investigation of a column-to-column joint. Engineering Structures, 127, pp.784-803. 
[5] Mozumder, R.A., Laskar, A.I. and Hussain, M., 2018. Penetrability prediction of microfine cement grout in granular soil using Artificial Intelligence techniques. Tunnelling and Underground Space Technology, 72, pp.131-144.

[6] Brown, S. and Needham, D., 2000. A study of cement modified bitumen emulsion mixtures. Asphalt Paving Technology, 69, pp.92-121.

[7] Al-Qadi, I.L., Gouru, H. and Weyers, R.E., 1994. Asphalt Portland cement concrete composite: laboratory evaluation. Journal of transportation engineering, 120(1), pp.94-108.

[8] Shannag, M.J., 2002. High-performance cementitious grouts for structural repair. Cement and concrete research, 32(5), pp.803-808.

[9] Ryan, T.P., 2007. Modern engineering statistics. John Wiley \& Sons.

[10] Glossop, R., 1960. The invention and development of injection processes part I: 19021850. Geotechnique, 10(3), pp.91-100.

[11] Habib, A.O., Aiad, I., El-Hosiny, F.I., and Mohsen, A., 2021. Studying the impact of admixtures chemical structure on the rheological properties of silica-fume blended cement pastes using various rheological models. Ain Shams Engineering Journal.

[12] Kanamarlapudi, L., Jonalagadda, K.B., Jagarapu, D.C.K. and Eluru, A., 2020. Different mineral admixtures in concrete: a review. SN Applied Sciences, 2(4), pp.1-10.

[13] Ma, C., Liu, Y., Zhou, H., Jiang, Z., Ren, W. and He, F., 2021. Influencing mechanism of mineral admixtures on rheological properties of fresh magnesium phosphate cement. Construction and Building Materials, 288, p.123130.

[14] Vasumithran, M., Anand, K.B. and Sathyan, D., 2020. Effects of fillers on the properties of cement grouts. Construction and Building Materials, 246, p.118346.

[15] Hassani, A., Taghipoor, M. and Karimi, M.M., 2020. A state of the art of semi-flexible pavements: Introduction, design, and performance. Construction and Building Materials, 253, p.119196.

[16] Hlail, S.H., Al-Busaltan, S. and Shaban, A.M., 2020, November. Sustainable Development of Highly Flowable Cementitious Grouts for Semi-flexible Pavement Mixture. In IOP Conference Series: Materials Science and Engineering (Vol. 928, No. 2, p. 022068). IOP Publishing.

[17] Tan, Y., Ouyang, J., Lv, J. and Li, Y., 2013. Effect of emulsifier on cement hydration in cement asphalt mortar. Construction and building Materials, 47, pp.159-164.

[18] Oruc, S., Celik, F. and Akpinar, M.V., 2007. Effect of cement on emulsified asphalt mixtures. Journal of materials engineering and performance, 16(5), pp.578-583.

[19] Niazi, Y. and Jalili, M., 2009. Effect of Portland cement and lime additives on properties of cold in-place recycled mixtures with asphalt emulsion. Construction and Building Materials, 23(3), pp.1338-1343.

[20] Ouyang, J., Pan, B., Xu, W. and Hu, L., 2019. Effect of water content on volumetric and mechanical properties of cement bitumen emulsion mixture. Journal of Materials in Civil Engineering, 31(6), p.04019085.

[21] Bocci, M., Grilli, A., Cardone, F. and Graziani, A., 2011. A study on the mechanical behaviour of cement-bitumen treated materials. Construction and building materials, 25(2), pp.773-778.

[22] Bołtryk, M. and Małaszkiewicz, D., 2013. Application of anionic asphalt emulsion as an admixture for concrete. Construction and Building Materials, 40, pp.556-565.

[23] Song, H., Do, J. and Soh, Y., 2006. Feasibility study of asphalt-modified mortars using asphalt emulsion. Construction and building materials, 20(5), pp.332-337.

[24] Ouyang, J., Zhao, J. and Tan, Y., 2018. Modeling mechanical properties of cement asphalt emulsion mortar with different asphalt to cement ratios and temperatures. Journal of Materials in Civil Engineering, 30(10), p.04018263.

[25] Hlail, S.H., Al-Busaltan, S. and Shaban, A.M., 2021, February. Durability Evaluation: Sustainable Semi-flexible Pavement Mixtures. In IOP Conference Series: Materials Science and Engineering (Vol. 1067, No. 1, p. 012076). IOP Publishing.

[26] ASTM, D2397, 2013. Standard specification for cationic emulsified asphalt. American Society for Testing Material. West Conshohocken, PA, United States. 
[27] ASTM, D6934, 2008. Standard test method for residue by evaporation of emulsified asphalt. American Society for Testing Material. Conshohocken, PA, United States.

[28] ASTM, D70, 2009. Standard test method for density of semi-solid bituminous materials (Pycnometer Method). American Society for Testing Material. Conshohocken, PA, United States.

[29] ASTM, D5, 2013. Standard test method for penetration of bituminous materials. American Society for Testing Material. West Conshohocken, PA, United States.

[30] ASTM, D113, 2007. Standard test method for ductility of bituminous materials. American Society for Testing Material. West Conshohocken, PA, United States.

[31] ASTM, D7226, 2013. Standard test method for determining the viscosity of emulsified asphalts using a rotational paddle viscometer. American Society for Testing Material. West Conshohocken, PA, United States.

[32] ASTM, D6929, 2010. Standard practice for freezing of emulsified asphalts. American Society for Testing Material. West Conshohocken, PA, United States.

[33] ASTM, D2042, 2015. Standard Test method for solubility of asphalt materials in trichloroethylene. American Society for Testing Material. West Conshohocken, PA, United States.

[34] ASTM, D244, 2009, Standard test methods and practices for emulsified asphalts. American Society for Testing Material. West Conshohocken, PA, United States.

[35] ASTM, D6999, 2012. Standard practice for miscibility of emulsified asphalts. American Society for Testing Material. West Conshohocken, PA, United States.

[36] ASTM, D6998, 2011. Standard practice for evaluating aggregate coating using emulsified asphalts. American Society for Testing Material. West Conshohocken, PA, United States.

[37] Lewis, R.C., 2018. Silica fume. In Properties of Fresh and Hardened Concrete Containing Supplementary Cementitious Materials (pp. 99-121). Springer, Cham.

[38] Koting, S., Karim, M.R., Mahmud, H., Mashaan, N.S., Ibrahim, M.R., Katman, H. and Husain, N.M., 2014. Effects of using silica fume and polycarboxylate-type super-plasticizer on physical properties of cementitious grout mixtures for semi-flexible pavement surfacing. The Scientific World Journal, 2014.

[39] Zarei, S., Ouyang, J., Yang, W. and Zhao, Y., 2020. Experimental analysis of semi-flexible pavement by using an appropriate cement asphalt emulsion paste. Construction and Building Materials, 230, p.116994.

[40] ASTM, C939-10, 2010. Standard test method for flow of grout for preplaced-aggregate concrete (flow cone method).

[41] ASTM, C942-10, 2010. Standard test method compressive strength of grouts for preplaced aggregate concrete in the laboratory.

[42] BSI, BS EN 12697-24, 2004. Bituminous mixturs-test methods for hot mix asphalt-part 24 Resistance to fatigue. British Standard Institution, London,UK.

[43] Abichou, T., Edil, T.B., Benson, C.H. and Bahia, H., 2004. Beneficial use of foundry by-products in highway construction. In Geotechnical Engineering for transportation projects (pp. 715-722).

[44] ASTM, ASTM C348-14, 2014. Standard test method for flexural strength of hyraulic-cement mortars.

[45] Husain, N.M., Karim, M.R., Mahmud, H.B. and Koting, S., 2014. Effects of aggregate gradation on the physical properties of semi-flexible pavement. Advances in Materials Science and Engineering, 2014.

[46] Zoorob, S.E., Hassan, K.E. and Setyawan, A., 2017. Cold mix, cold laid semi-flexible grouted macadams, mix design and properties. In Performance of Bituminous and Hydraulic Materials in Pavements (pp. 105-112). Routledge.

[47] Koting, S., Karim, M.R., Mahmud, H., Mashaan, N.S., Ibrahim, M.R., Katman, H. and Husain, N.M., 2014. Effects of using silica fume and polycarboxylate-type super-plasticizer on physical properties of cementitious grout mixtures for semi-flexible pavement surfacing. The Scientific World Journal, 2014. 